\title{
Parteien und Demokratie in Sachsen 1990 bis 2015
}

\author{
Werner J. Patzelt
}

\section{Parteien und Demokratie}

Es ist ganz richtig, Parteien und Demokratie zusammenzudenken. Eine Demokratie im Flächen- und Massenstaat kommt nämlich nicht ohne Repräsentation aus, repräsentative Demokratie aber nicht ohne Parteien. Am besten erfüllen Parteien ihre Aufgaben und dienen sie einer repräsentativen Demokratie, wenn sie sowohl im Parlament als auch im Wahlkreis wirkungsvoll handeln. Einesteils tun sie das durch starke Verankerung in der Gesellschaft, wenn sie nämlich viele und auch ihrerseits gut vernetzte Mitglieder haben, diese auch an der innerparteilichen Willensbildung beteiligen sowie die Interessen und Meinungen der Bevölkerung in die öffentliche Diskussion bzw. in die politische Willensbildung einbringen - und zwar hin bis zur Entscheidungsfindung in Parlament und Regierung. Andernteils erfüllen Parteien ihre Aufgabe gut im Parlament, wenn sie wirkungsvoll die Regierung kontrollieren, problemlösende Gesetze beschließen sowie - in einem parlamentarischen Regierungssystem wie dem sächsischen - durch die Bildung von Koalitionen und durch die Sicherung von deren innerem Zusammenhalt verlässliche parlamentarische Mehrheiten für eine kontinuierliche Regierungspolitik sorgen. Dafür braucht es dann Teamgeist oder „Fraktionsdisziplin“. In der Erfüllung dieser Aufgaben entstand auch Sachsens heutiges Parteiensystem.

\section{Prägefaktoren der Parteien Ostdeutschlands}

Sachsens Parteiensystem, seinerseits Teil der sehr besonderen ostdeutschen Parteienlandschaft, ist ein regional differenzierter Teil des deutschen Parteiensystems. Wie dieses ist es aus einer quer über Deutschland gemeinsamen Geschichte gewachsen, allerdings - im Unterschied zu den Parteiensystemen der westdeutschen Länder - mit besonderen Merkmalen, die klar auf die SED-Diktatur zurückgehen.
Diese hatte nämlich die traditionellen deutschen Parteiströmungen im „Demokratischen Block“ der „Nationalen Front“ zusammengefasst und dabei unter die Herrschaft der Kommunistischen Partei gebracht. Erster Schritt dazu war, dass im Jahr 1946 die - überall in der Sowjetischen Besatzungszone mit so großen Hoffnungen neu aufgelebte - SPD in eine Zwangsvereinigung mit der KPD getrieben wurde und man dafür sorgte, dass in der so entstandenen „Sozialistischen Einheitspartei Deutschlands" nicht die sozialdemokratischen Positionen, sondern die kommunistischen Gestaltungsabsichten ausschlaggebend wurden. Anschließend wurden jene Parteien der Führung der SED unterstellt, welche die übrigen, seit Jahrzehnten in Deutschland üblichen politischen Strömungen vertraten. Die CDU als Organisation der christlich-konservativen Bevölkerungsteile wurde ebenso wie die Liberaldemokratische Partei Deutschlands (LDPD) als Organisation des politischen Liberalismus zum Teil des „Demokratischen Blocks“ und hatten dort die Weisungen der SED zu befolgen. Gleiches geschah mit den viel weniger von der deutschen Parteiengeschichte getragenen Neugründungen, nämlich der Demokratischen Bauernpartei Deutschlands (DBD) und der Nationaldemokratischen Partei Deutschlands (NDPD), welche die Trennlinie zwischen ehemaligen Nazis und Nicht-Nazis gesellschaftsintegrierend überwinden sollte. Im Übrigen hatte die SED bald schon jenen „vorpolitischen Raum" planiert, in dem Parteien üblicherweise wurzeln. Von der Freien deutschen Jugend (FDJ) über den Kulturbund bis hin zum Freien Deutschen Gewerkschaftsbund (FDGB) hatte sie so gut wie alle zivilgesellschaftlichen Organisationen, allein die Kirchen aufgrund mangelnder Erfolgsaussicht ausgenommen, zu eigenen Satelliteninstitutionen gemacht und unterband bis 1989, als das „Neue Forum“ um mutige Oppositionelle herum aus der Gesellschaft hochwuchs, das Aufkommen von Alternativen zu ihnen. 


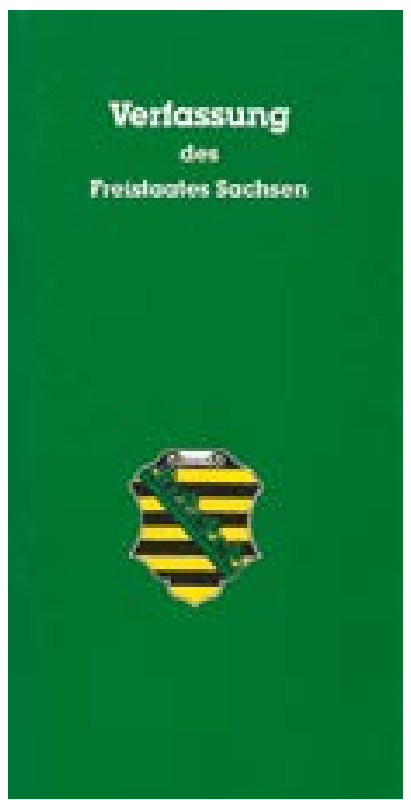

Verfassung des Freistaates Sachsen vom 27. Mai 1992, Ausgabe der Pressestelle des Sächsischen Landtags, 1992
Die Neuentstehung eines demokratischen Parteiensystems auf dem Gebiet der DDR bzw. in Sachsen begann damit, dass sich - unter zunächst dem Namen SDP für „Sozialdemokratische Partei in der DDR“ - die SPD auf konspirative Weise Anfang Oktober 1989 neu gründete und im September des Folgejahres mit der SPD vereinte. Die schon bestehenden Parteien CDU und LDPD befreiten sich im Spätherbst 1989 von der Vormundschaft der SED und fingen schon bei der Vorbereitung der freien Volkskammerwahl im Frühjahr 1990 an, auf verschiedene Weise mit ihren westdeutschen Partnerparteien zusammenzuwachsen. Bei der CDU nahm das die Form an, dass sie mit den im Oktober 1989 bzw. Januar 1990 neu gegründeten Parteien „Demokratischer Aufbruch“ (DA) und „Deutsche Soziale Union“ (DSU) als „Allianz für Deutschland“ auftraten. In die CDU mündete im Sommer 1990 dann auch die Geschichte der Demokratischen Bauernpartei Deutschlands, während die NDPD zum Teil der FDP wurde. Mit Ausnahme von Bündnis 90 sowie der in „Partei des Demokratischen Sozialismus" (PDS) umbenannten SED waren somit im Herbst 1990 sowohl die alten als auch die neuen Parteien der DDR in zuvor westdeutschen Parteien aufgegangen. Diesen Prozess beschleunigte erst recht die Vorbereitung der ersten Parlamentswahlen in den neuen Bundesländern im Oktober 1990 sowie der ersten gesamtdeutschen Bundestagswahl im Dezember 1990.

Dabei entstanden Ostdeutschlands und Sachsens „bundesdeutsche Parteien“ einesteils „,von oben nach unten“. Es gab ja - mit Ausnahme von SPD und Bündnis 90 - in allen Parteien die Mandatsträger aus der letzten sozialistischen Volkskammer sowie die übrigen Funktionsträger aus DDR-Zeiten. Diese wurden zwar, je nach Partei mehr oder minder tiefgreifend, durch andere Personen ausgetauscht. Doch natürlich blieben, wenn bald auch mit veränderten Spielregeln, die alten Führungsstrukturen bestehen, da sie ja von den Reformern gleichsam „nur“ zu erobern waren. Ferner waren da bald schon jene Westdeutschen, die zunächst als Organisations- und Wahlkampfhelfer ins jeweilige ostdeutsche Partnerland kamen, mitunter auch als Spitzenkandidaten, und die dann oft Führungsämter sowie Mandate der ostdeutschen Landesparteien übernahmen. Von ihnen aus gestalteten sie den Wandlungsprozess „ihrer“ Partei bald merklich mit. Und weil diese Westdeutschen nicht nur Wissen um die politischen Spielregeln des neuen Systems mitbrachten, sondern oft genug auch Kontakte und finanzielle Unterstützung aus dem Westen den Führungsebenen der sich erneuernden Parteien erschlossen, führte dies ebenfalls $\mathrm{zu}$ einem Wachstumsschub „Von oben“. Zu ihm trug nicht minder bei, dass die politische Macht über die Volkskammer-, Bundestags- und Landtagswahlen des Jahres 1990 neu verteilt wurde, also bald zu einer wichtigen innerparteilichen Rolle gelangen konnte, wem es ganz persönlich gelang, für eine absehbar erfolgreiche Partei zunächst in die Volkskammer und dann in den Bundestag oder in einen der ostdeutschen Landtage einzuziehen. Tatsächlich wurden die Parlamentsfraktionen sowie Abgeordneten mit ihren Ressourcen für Wahlkreisbüros und persönliche „Parteiabgaben“ rasch zum Rückgrat der neuen Parteien. Allerdings akzeptierte ein nennenswerter Teil der ersten ostdeutschen Abgeordnetengeneration diese Parteiführungsaufgabe nicht, sondern versuchte sich zunächst in einer Rolle als „unparteiischer Volksvertreter“. Auf diese Weise verzögerte sich das Zusammenwachsen dessen, was Parteien einerseits im Parlament, andererseits in den Wahlkreisen an der gesellschaftlichen Basis zu leisten haben.

Andernteils wurden die neuen Parteiensysteme Ostdeutschlands sehr stark auch „,von unten“ her geprägt. Es war ja schon die Friedliche Revolution, die alledem voranging, eine von unten nach oben wirkende Bewegung. Sie begann mit der inneren Kündigung vieler DDR-Bürger gegenüber dem SED-Staat, setzte sich fort in der Fluchtbewegung seit dem Frühsommer 1989, gipfelte auf in den Montagsdemonstrationen und fand ihren Abschluss an den Wahlurnen der Volkskammer-, Bundestags- und Landtagswahlen des Jahres 1990. Nicht minder wichtig war, dass den schon bestehenden Parteien ihre Mitglieder davonliefen, allen voran der SED. Das hatte bei dieser Partei viel mit der Diskreditierung ihrer Glaubwürdigkeit und dem Überdruss am sozialistischen Staat zu tun. Bei den anderen Parteien des „Demokratischen Blocks“ kam hinzu, dass eine Parteimitgliedschaft fortan für eine gelingende Berufspraxis so gut wie funktionslos wurde. Jedenfalls schmolz den zu DDRZeiten etablierten Parteien ihre Basis dahin, zumal die sich reformierende DDR und der diese aufnehmende westdeutsche Teilstaat den Parteien auch nicht mehr jene vielen Gelder zur Verfügung stellte, welche für die Aufrechterhaltung mitunter ausufernder Organisationsstrukturen erforderlich waren. Zudem geriet nach Einführung der D-Mark die ostdeutsche Gesellschaft in eine Entwicklungs- und Umschichtungskrise: Es standen sehr vielen Leuten die Schließung von Betrieben, kommende Arbeitslosigkeit sowie umfangreiche Notwendigkeiten 
einer persönlichen Neuorientierung vor Augen. In dieser Lage wurde politische Beteiligung für die meisten zu einem nachrangigen Ziel. Eher herrschte der Eindruck vor, was man selbst leisten könne, habe man bereits in die Friedliche Revolution sowie in die Wahlkämpfe des Jahres 1990 eingebracht; und also kümmere man sich zu Recht jetzt vor allem um sich und die eigene Familie.

Doch gerade in einer solchen Lage eröffneten sich für gar nicht wenige ganz unerwartete, auch ganz unterschiedlich genutzte Chancen für eine politische Laufbahn. Dabei hing es auch sehr stark von Zufällen ab, ob man 1990 als Kandidat für eine der drei so weichenstellenden Wahlen aufgestellt wurde. Später erst prägten das politisch-praktische Können sowie der eigene Persönlichkeitstyp, was man aus den sich bietenden Gelegenheiten $\mathrm{zu}$ machen verstand. Doch obwohl gar nicht wenige aus der ersten Generation ostdeutscher Parlamentsabgeordneter zuvor schon gesellschaftlich oder im kommunalen Bereich politisch tätig waren, gelangte auf diese Weise eine überwiegend neue politische Elite in die Führungspositionen der Parteien. Sie war freilich auch aufgrund der fortan tiefgreifend veränderten Handlungsumstände - ziemlich anders als die abgetretene DDR-Politikerschaft ausgerichtet.

Oberflächlich sahen Ostdeutschlands Landesparteien zwar schon bald wie Abbilder ihrer westdeutschen Partnerverbände aus. Sie hatten Parlamentsabgeordnete, die oft auch regionale Parteiführer waren; sie hatten ihre Landes- und Regionalgeschäftsstellen; sie traten an und auf als Gliederungen fortan bundesweiter Parteien. Neben Bündnis 90, mit dem sich die westdeutschen Grünen nicht leicht taten, war vor allem die PDS eine Ausnahme: Als Nachfolgerin der Staatspartei der DDR hatte sie im Westen einfach kein Gegenstück. Doch die wichtigste, höchst folgenreiche und dennoch auf den ersten Blick nicht leicht erkennbare Besonderheit war die, dass in den neuen Bundesländern den Parteien der vorpolitische Raum als Wurzelgrund fehlt. Das heißt: Es gab kein Geflecht lebendiger zivilgesellschaftlicher Organisationen, über das sie flächendeckend in der Gesellschaft hätten verankert sein, auf diese Einfluss nehmen und umgekehrt neue, in lebenspraktischen Dingen schon bewährte Mitglieder hätten gewinnen können. Gleichsam schwebte das neue Parteiensystem wie ein Luftkissenboot über der ostdeutschen Gesellschaft. Obendrein dem westdeutschen Parteiensystem eher nachgebaut als dieses in den neuen Bundesländern nachlebend, misslang auf diese Weise vielfach die Herstellung auch emotionaler Identifikati- on zwischen den Bürgern und „ihren“ Parteien. Insgesamt kam es nicht zu Beziehungen zwischen den Parteien und den von ihnen ansprechbaren Bevölkerungsteilen, die auch mit dichtgesponnenen und stabilen sozialen Netzwerken untersetzt gewesen wären.

Zweierlei war die - im Lauf der Jahre immer deutlicher zu erkennende - Folge. Erstens kam es zur erheblichen Volatilität im Wahlverhalten, also zur „Flatterhaftigkeit“ oder „Wankelmütigkeit“ des Wahlvolks. Zweitens entstanden „Repräsentationslücken“, das heißt Bevölkerungsschichten, die sich von keiner im Parlament agierenden Partei vertreten sahen. In solche Lücken drangen bald schon vom rechten Rand her Protestparteien ein, zunächst die DVU und die NPD, später die AfD. Sie spielten - und spielen - wegen jener besonders geringen gesellschaftlichen Verankerung der Parteien in den neuen Bundesländern auch durchweg eine wichtigere politische Rolle als im Westen des Landes. Am linken Rand allerdings vollzog sich dergleichen in den neuen Bundesländern nicht: Die PDS bzw. LINKE verstand von Anfang an bis ganz ans Ende ihres politischen Spektrums Bürgerinnen und Bürger anzusprechen sowie an sich zu binden. Im Grunde war die PDS sogar einige Jahre lang geradezu die einzige „Volkspartei“ der neuen Bundesländer. Ein Großteil ihrer Mitglieder bestand aus „staatstragenden Leuten“, denen einfach der von ihnen geschätzte Staat abhanden gekommen war, und die ihren Zorn darüber sowie ihre Hoffnungen im neuen System nunmehr in der PDS aufgehoben und vertreten wussten.

Vor dem Hintergrund all dessen, und vermittelt über die Gründungswahlen vom Oktober 1990, hatte zweierlei besonders weitreichende Folgen. Zum einen war das die Wirkung anziehender Persönlichkeiten. Wo - wie Kurt Biedenkopf in Sachsen oder Manfred Stolpe in Brandenburg - eben solche an der Spitze von Regierungen und Parteien standen sowie sich dort hielten, verfestigten sich um sie herum schon rasch Parteimilieus. Davon zehrt bis heute in Sachsen die CDU, in Brandenburg die SPD. Und wo wie mit Bernhard Vogel in Thüringen - wenigstens etliche Jahre lang eine solche Persönlichkeit agierte, dort zeigte sich immerhin zeitweise ein ähnlicher Effekt.

Zum anderen wurde sehr folgenreich, wie weitgehend in den Parteien das aus DDR-Zeiten überkommenen Politikpersonal durch neue, reformorientierte Kräfte verdräng. In der sächsischen CDU gelang eine solche Erneuerung ziemlich gut, nämlich dank des Wirkens von rebellischen Politikern wie Arnold Vaatz. Das gehört zu den wirklich wichtigen Ursachen der 
1 Vgl. Christian Demuth/Jakob Lempp (Hrsg.): Parteien in Sachsen. Berlin 2006

Wahlergebnisse der CDU bei den Landtagswahlen 1990 bis 2014

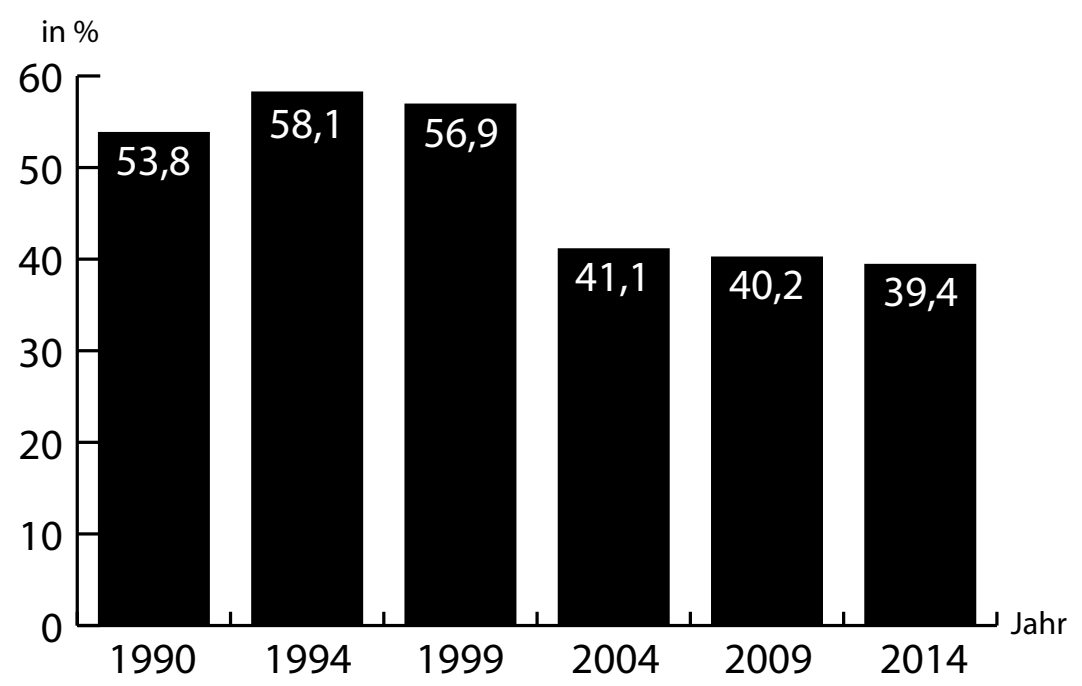

Rennen machen. Es entstand stattdessen eine bis heute anhaltende, wenn auch immer mehr unterspülte Vorherrschaft der CDU. Rechtzeitig statt mit einem ehemaligen Ost-CDU-Politiker mit dem intellektuell glanzvollen Kurt Biedenkopf als Spitzenkandidaten angetreten, gewann die CDU mit 53,8 Prozent der Stimmen 1990 die erste Landtagswahl, baute 1994 ihren Vorsprung auf 58,1 Prozent aus und büßte ihre absolute Mehrheit erst 2004 mit nur noch 41,1 Prozent ein, und zwar vor allem aufgrund von Ungeschicklichkeiten ihrer Spitzenleute.

Kurt Biedenkopf erklärte nämlich leichtfertig in der Siegerlaune des Wahlabends vom 19. September 1999, nun beginne seine letzte Amtsperiode als Ministerpräsident. Dadurch lenkte er die politische Aufmerksamkeit auf die Amtsnachfolge, unternahm aber nichts, um diese auch zu regeln. Das brachte seinen Finanzminister Georg Milbradt, der die Nachfolge anstrebte, zum Versuch des Aufbaus von um ihn gelagerten Machtstrukturen, und zwar ausgerechnet in der für den Ministerpräsidenten politisch zentralen Landtagsfraktion der CDU. Kurt Biedenkopf unterband das verständlicherweise durch Entlassung seines Finanzministers. Der aber setzte den Kampf um die Macht, politisch ganz korrekt, von der Parteibasis der CDU her fort. Er betonte das Verkümmern der Partei im Schatten des Ministerpräsidenten, kündigte seine Kandidatur als Parteivorsitzender an und stellte eine - auch künftig die CDU-Macht sichernde - Parteireform in Aussicht. Er gewann diesen Machtkampf, als er 2001 zum Landesvorsitzenden der CDU gewählt wurde. Kurt Biedenkopf, durch eine gegen ihn geführte Medienkampagne ohnehin zermürbt, trat im Januar 2002 mit Wirkung ab 18. April 2002 als Regierungschef zurück, woraufhin der CDUVorsitzende Milbradt zum Ministerpräsidenten gewählt wurde.

Dieser Machtkampf hatte allerdings tiefe Zerwürfnisse innerhalb der sächsischen CDU bewirkt. Georg Milbradt, seinem Wesen und seiner Biographie nach ohnehin viel mehr ein Mann der Exekutive denn einer Partei, schaffte es denn auch nicht, die CDU zu befrieden. Sein anfänglicher Rückhalt in der Partei verfiel. Ganz in der Regierungsarbeit aufgehend, obendrein nicht selten persönlich unzugänglich, blieb unter ihm die Partei erst recht im Schatten des Ministerpräsidenten. Der aber agierte in einer anderen Zeit als sein Vorgänger: Während dieser durch den Elan von Visionen sowie die vorantreibende Anfangserfahrung ihrer Realisierbarkeit getragen wurde, sah sich Milbradt mit vielerlei „Mühen der Ebene“ kon- 

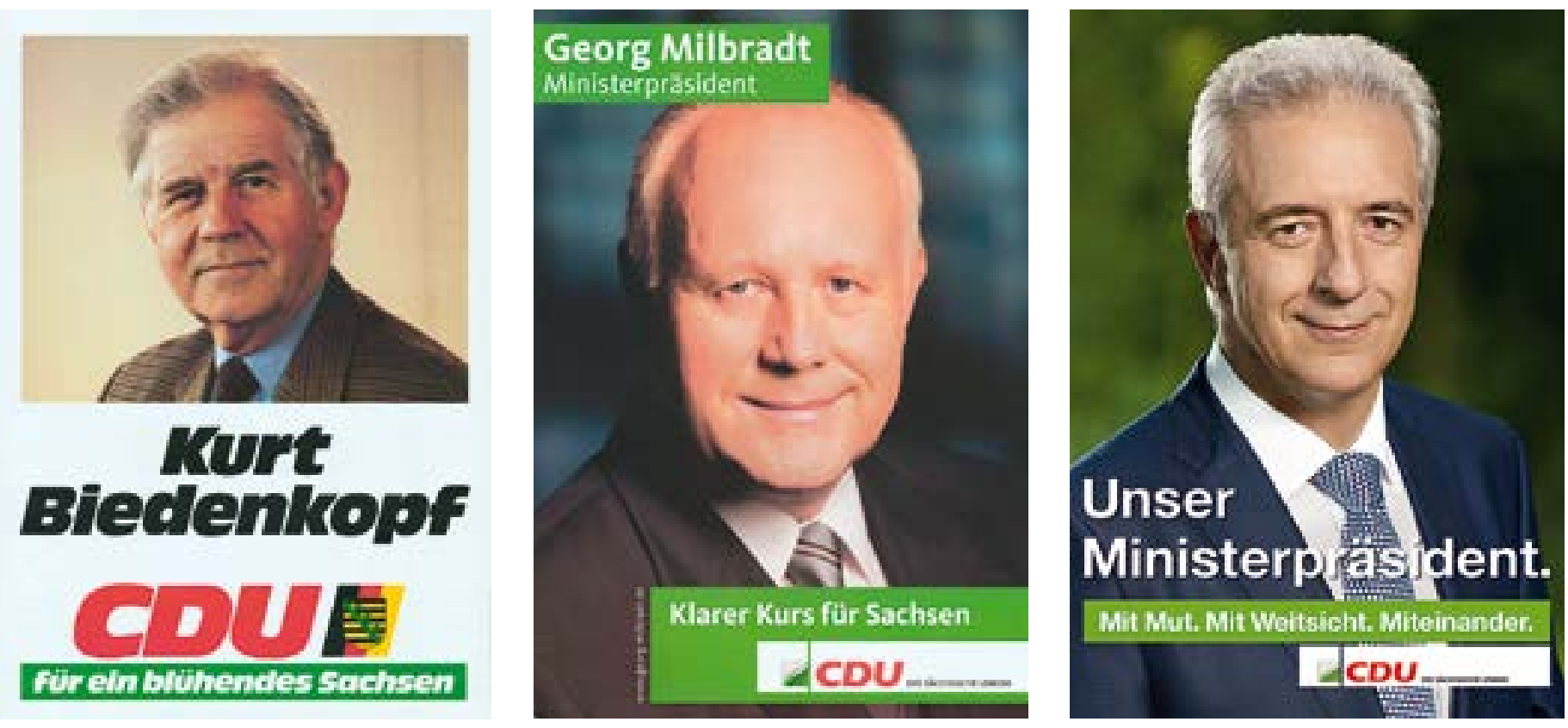

frontiert, die - eben aufgrund des sich ringsum einstellenden Grunderfolgs - bald schon als ärgerliche, nun endlich zu beseitigende Unzulänglichkeiten der Regierungsarbeit empfunden wurden. Aus beflügelnder Vorfreude auf künftigen Aufstieg wurde so ein stetes Leiden an den damit verbundenen Anstrengungen. Obendrein verband sich mancherlei inhaltliche Unzufriedenheit mit etlicher Enttäuschung über den Ministerpräsidenten Milbradt, der als ein sehr gestrenger Sparkommissar wirkte, noch nicht aber - wie jetzt im Rückblick - alle von der künftigen Rendite solcher Politik überzeugt hatte.

Bei der ersten von Georg Milbradt als Spitzenkandidat zu verantwortenden Landtagswahl verlor die CDU 2004 denn auch ihre absolute Mehrheit und wurde in eine Koalition mit der SPD gezwungen. Vervollständigt wurde das Debakel, als der amtierende Ministerpräsident bei der Neuwahl des Ministerpräsidenten die erforderliche Mehrheit im ersten Wahlgang verfehlte. So angeschlagen, begann eine erst recht glanzlose zweite Amtszeit. Während dieser wurde 2007 sichtbar, dass sich die Landesbank Sachsen - und zwar unter den Augen des als Finanzfachmann angesehenen Ministerpräsidenten - finanziell übernommen hatte, ja vor dem Bankrott stand. Der Rücktritt des damaligen Finanzministers reichte nicht aus, den politischen Sturm von Georg Milbradt fernzuhalten. Im April 2008 erklärte er dann seinen Rücktritt von sämtlichen politischen Ämtern. Sein Nachfolger wurde als Parteivorsitzender und als Ministerpräsident Stanislaw Tillich, der erste aus Sachsen (und der Ost-CDU) stammende Regierungschef des neu begründeten
Freistaats. Eine lange politische Laufbahn unter anderem als Europaabgeordneter, Staatsminister für Bundes- und Europaangelegenheiten, später für Umwelt und Landwirtschaft, noch später für Finanzen - hatte er ohne Abnutzungsspuren hinter sich gebracht. Auch trat er stets besonnen und gewinnend auf. In seiner Zeit legten sich die aus dem Kampf um Biedenkopfs Nachfolge rührenden Verstimmungen. Doch mehr als ein „Weiter so!“ auf den zielführend gelegten Schienen der Gründungsära unter Ministerpräsident Biedenkopf und Finanzminister Milbradt versuchte er nicht. Ohnehin blieb er seit Amtsantritt in Koalitionen eingebunden: zunächst mit der SPD, zwischen 2009 und 2014 mit der FDP, seither wieder mit der SPD.

Zur großen Herausforderung seiner Regierungszeit und Regierungskunst wurde seit dem Spätherbst 2014 das von der Bundesebene zu verantwortende, von der Landesebene aber auszugestaltende Einwanderungsgeschehen nach Sachsen. Es traf die CDU an ihrer Achillesferse. Die Problematisierung des Einwanderungsgeschehens gilt nämlich in Deutschland als ein „rechtes Thema“. Also begann der Protest gegen die Folgen einer bis dahin höchstens ansatzweise regulierenden Einwanderungs- und Integrationspolitik die politischen Kräfte rechts der CDU zu einen, und zwar umso mehr, als selbst die weiter rechts als die Bundes-CDU eingestellte Sachsenunion sich nicht gegen die Anmutung zu wehren vermochte, Teil des rot-rot-grün inspirierten Anti-Rechts-Blocks zu werden. Den rechten Rand thematisch und programmatisch so einzubinden, dass rechts von der CDU keine nennenswerte politische Kraft aufkommen konnte, hatte zwar
Kurt Biedenkopf, Wahlplakat der CDU, 1990 Foto: Konrad-Adenauer-Stiftung

Georg Milbradt,

Wahlplakat der CDU, 2004

Foto: Konrad-Adenauer-Stiftung

Stanislaw Tillich,

Wahlplakat der CDU, 2014

Foto: CDU Sachsen 
Wahlergebnisse der NPD bei den Landtagswahlen 1999 bis 2014 auch die sächsische CDU schon seit Jahren unterlassen. Nun aber begann sich abzuzeichnen, dass die CDU langfristig jene Wählerschichten verlieren würde, die von der AfD über die Sympathisantenschaft der von Dresden ausstrahlenden PEGIDA-Bewegung bis hin zur NPD reichen.

Auch dieses Versäumnis trug zur weiteren Erosion der Basis der sächsischen CDU bei. Nicht nur sanken - wie bei allen aus der DDR überkommenen Parteien - ihre Mitgliederzahlen, nämlich von etwa $37.000 \mathrm{im}$ Jahr 1990 auf 25 Jahre später rund 12.000 , was sich natürlich in eine weitere Ausdünnung ihrer gesellschaftlichen Netzwerkstrukturen umsetzte. Auch verlor die CDU nicht nur im Landtag die absolute Mehrheit und gibt sich seither - aufgesetzt oder indolent - mit noch geringeren Stimmenanteilen zufrieden, als sie bei Milbradts Landtagswahlkampf als katastrophal gegolten hatten. Sondern obendrein nahm die Zahl ihrer kommunalen Mandatsträger mehr und mehr ab, so dass im Grunde nur noch die zehn Landratsposten von der einst - außerhalb der Großstädte Leipzig und Chemnitz - wie unerschütterlich wirkenden CDU-Dominanz zeugen. Den Staat trägt die sächsische CDU seither zwar immer noch, obendrein mit ansehnlicher Bilanz. Doch sie ist ins Wanken geraten.

\section{Zwischen CDU und rechtem Rand}

Bei den Gründungswahlen dominierte die CDU das gesamte politische Spektrum zwischen der Mitte und dem rechten Rand. Zwar machten ganz am Anfang noch die Republikaner und die DSU ein wenig von sich reden, und breitete sich rasch eine rechtsradikale Szene zumal in der Sächsischen Schweiz aus. Desgleichen gab es schon anfangs der 1990er Jahr vereinzelte Aufrufe an Künstler, sie sollten die Bühnen im „rechtsradikalen Dresden“ meiden. Doch gar nicht wenigen klang es einleuchtend,

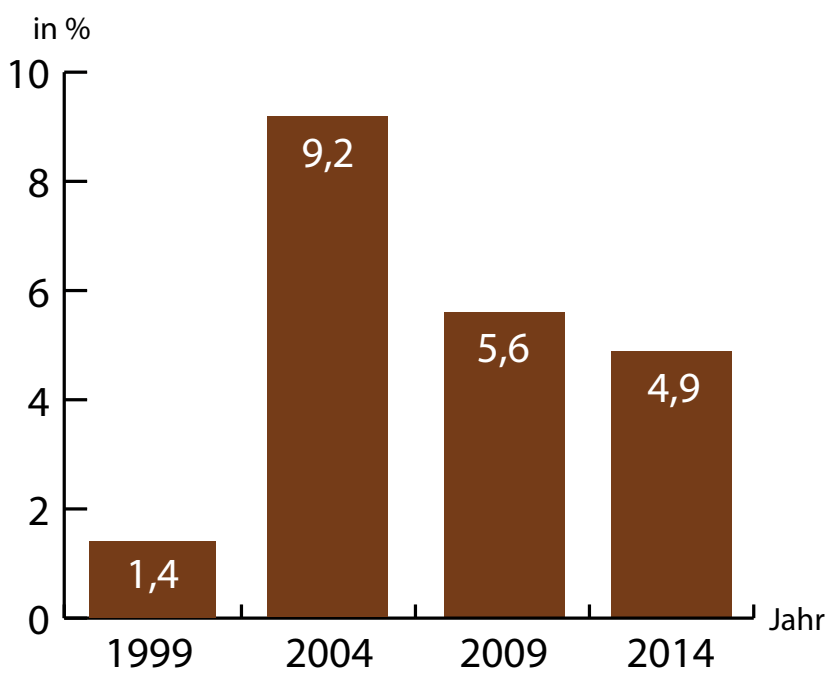

als Ministerpräsident Biedenkopf im Jahr 2000 behauptete, „seine Sachsen“ wären gegen Rechtsextremismus immun. Auch diese Fehleinschätzung dürfte zur Sorglosigkeit der CDU angesichts ihrer für das Gemeinwesen strategisch wichtigen Aufgabe beigetragen haben, rechts von sich keine Partei hochkommen zu lassen.

Die Dinge entwickelten sich dann auch anders, und zwar keineswegs zum Vorteil der sächsischen Demokratie. 2004, als die CDU ihre absolute Mehrheit verlor, zog die NPD erstmals in den Sächsischen Landtag ein - und zwar mit nicht weniger als 9,2 Prozent der Stimmen. Mit 5,6 Prozent gelang ihr das auch im Jahr 2009. Erst bei der Wahl von 2014 blieb sie mit 4,95 Prozent ganz knapp unter der Sperrklausel. Dafür zog damals die neugegründete AfD mit 9,7 Prozent in den Landtag ein, was auf knapp 15 Prozent sich rechts von der CDU verortende und von den bislang etablierten Parteien nicht mehr erreichbare Wähler hinausläuft. Die AfD war zwar aus einer Art Elitenkritik gegen die Euro-Rettungspolitik der - CDU-geführten Bundesregierung entstanden, fand mit ihren Sorgen aber großes öffentliches Echo, gelangte 2013 mit 4,7 Prozent fast in den Bundestag und 2014 mit 7,1 Prozent tatsächlich ins Europäische Parlament. In Vorbereitung auf die ebenfalls 2014 anstehenden Landtagswahlen in Brandenburg, Sachsen und Thüringen erweiterte die AfD ihre Programmatik dann um Themen, die jahrelang im rechten bzw. konservativen Bereich der CDU ihren Platz und ihrer Wortführer hatten, doch mehr und mehr von der sich „sozialdemokratisierenden“ Bundesspitze der CDU als „für die CDU inakzeptabel weit rechts" behandelt wurden. Zwar positionierte sich die Sachsenunion vielfach weiterhin auf bisherigen CDU-Positionen und somit etwas rechts von der „neuen Mitte“ der CDU. Auch damit aber konnte sie nicht verhindern, dass politischer Raum rechts von der CDU frei geworden war und zunächst von der NPD, dann von der AfD besiedelt wurde.

Der leichtere Gegner für die CDU war - und bleibt - die NPD, die derzeit in Sachsen knapp 800 Mitglieder umfasst. Tatsächlich rechtsradikale Positionen besetzend und mit fließendem Übergang zum gewalttätigen rechtsextremistischem Rand, verfing der NPD gegenüber eine klare Ab- und Ausgrenzungsrhetorik. Auch die konnte aber Wähler, die von der CDU „nach rechts" weggegangen waren, nicht wieder an die Sachsenunion als staatstragender Partei binden. Erst recht konnte eine solche Schwungmasse von Bürgern mit rechter Grundeinstellung nicht von Parteien links der CDU gewon- 
nen werden, obwohl sich mitunter durchaus erwähnenswerte Wählerströme zwischen NPD und PDS bzw. LINKE erkennen ließen. Also identifiziert sich ein erheblicher Teil von Bürgern mit sehr rechter politischer Haltung weiterhin mit der NPD.

Doch ein anderer, wohl klar größerer Teil scheint auf eine Partei wie der bayerischen CSU vor Horst Seehofers Zeiten zu hoffen: klar rechts der Mitte, doch nicht rechtsradikal, sozial orientiert sowie stetig in ihrem Kurs und somit von vernünftigen Leuten wählbar. Solche Hoffnungen schien die AfD zu erfüllen. Deshalb schaffte sie es, in Sachsen derzeit etwa 800 Mitglieder umfassend, auch 2014 in den Landtag. Allerdings schadete ihrem Ansehen und ihrer Attraktivität sehr, dass schon im Folgejahr die an den Wahlurnen besonders erfolgreichen sächsischen und brandenburgischen Landesverbände im innerparteilichen Machtkampf zwischen ihren Führern und den westdeutschen Parteigründern ins Licht einer „NPD light" gerückt wurden. Eine solche aber hat bloß ein bescheidenes Wählerreservoir. Es dürfte freilich wachsen, falls die Sorge um die Folgen der - lange Zeit ganz ungebremsten Einwanderung nach Deutschland auf Dauer als fixe Idee von politisch allzu Rechten behandelt wird. Somit ist noch unklar, ob im von der CDU aufgegebenen rechten Rand des politischen Spektrums eine bestandsfähige, staatstragende Partei von einiger Dauer entstehen wird. Bislang gibt es sie jedenfalls nicht. Die auf diese Weise aufgetane Repräsentationslücke, fallweise durch Protestparteien geschlossen, droht $\mathrm{zu}$ einem Risiko für Sachsens bislang stetige demokratische Entwicklung zu werden.

Das zeigt sich an der von Dresden ausgehenden PEGIDA-Bewegung. Genährt wurde sie - und wird sie wohl weiterhin - von Sorgen über die Folgen der jahrelang ziemlich passiven deutschen Einwanderungspolitik sowie von der Empörung über jene politischen Führer und Teile der politischen Öffentlichkeit, die in der Einwanderungspolitik einen Kurswechsel nicht wollen oder nicht wagen. Mit diesem Thema, obendrein besonders akzentuiert durch erhebliche Islamfürchtigkeit, gewann PEGIDA Aufsehen und eine durchaus nennenswerte, wenn auch oft nur klammheimliche, Anhängerschaft weit über Dresden hinaus. Obendrein erweist sich mehr und mehr der Versuch als scheiternd, die Einwanderungs- und Integrationsprobleme Deutschlands als ein „rein fiktives Thema“ auszugeben.

Was allerdings gelang, war die - bis mindestens zum Sommer 2015 ganz kontrafaktische - Etikettierung der Dresdner PEGIDA-Demonstra-

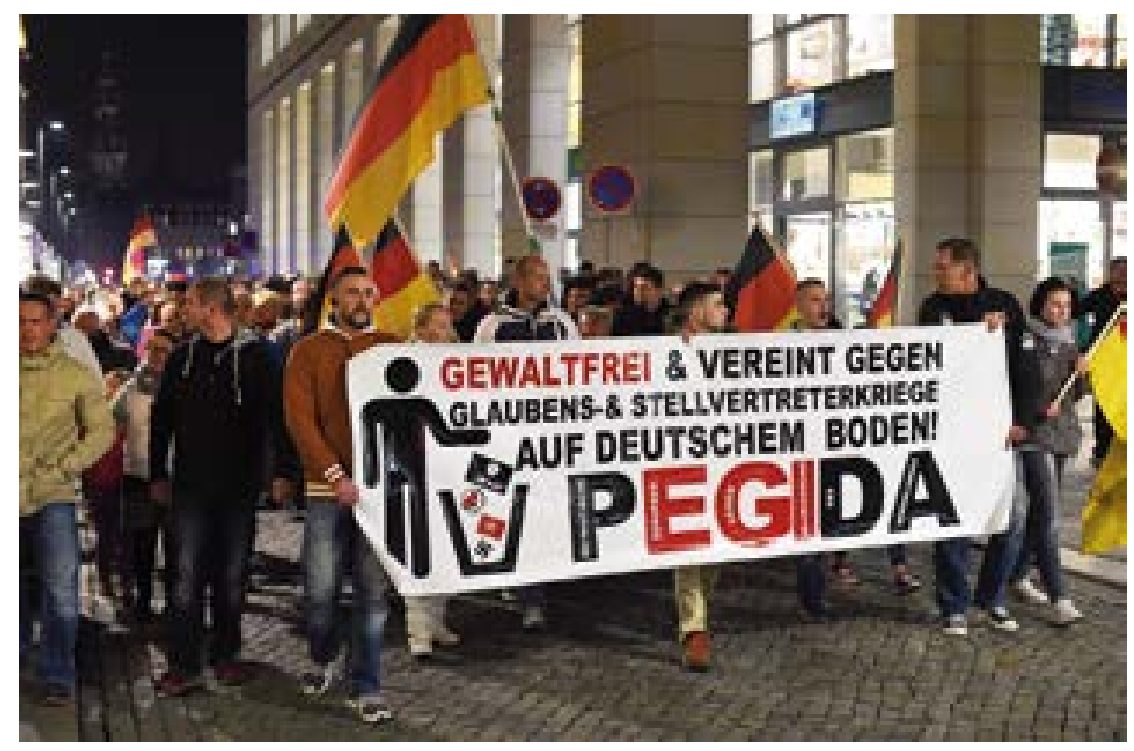

tionen als einer Gruppe von rundum rassistischen Rechtsradikalen. Den Schulterschluss mit solchen zu suchen, wurde fortan für mehr und mehr wirkliche Rechtsradikale und Rechtsextremisten attraktiv. Verbindet sich fortan das von der CDU - mangels eigener Integrationsanstrengungen - in seiner Eigendynamik belassene rechte Wählerpotential mit dem klar radikalen und extremistischen rechten Rand, so entsteht aus ihm, sowie aus empörten Wählern anderer Parteien, ein Stimmenpotential, das die CDU von rechts her ebenso zum Schrumpfen bringen dürfte, wie es im Westen der SPD nach dem Aufkommen der - vielfach von ihr sich abspaltenden - Grünen widerfuhr. Der sächsischen Demokratie wäre mit einer solchen neuen Rechten gewiss nicht gedient.

\section{Vom linken Rand bis zur Mitte}

Eine Repräsentationslücke am linken Rand gibt es in Sachsen nicht. Die Linkspartei - ihrerseits zu einer durchaus anderen, viel mehr ideologiegetriebenen Partei geworden, als sie die überwiegend pragmatische PDS einst war versteht sich als „natürlicher Verbündeter" auch höchst radikaler linker Gruppierungen, wie sie zumal in Leipzig immer wieder in Erscheinung treten. Sympathie für diese gibt es auch ziemlich weit hinein in die Reihen der GRÜNEN und der SPD. Doch während die CDU zwischen der Repräsentationslücke am rechten Rand und der politischen Mitte die gesamte politische Willensbildung kanalisiert, tun dies zwischen dem linken Rand und der politischen Mitte nicht weniger als drei Parteien. Obendrein bestehen zwischen ihnen ziemlich komplizierte Beziehungen.
PEGIDA-Demonstration in Dresden, 2015 Foto: wikimedia 


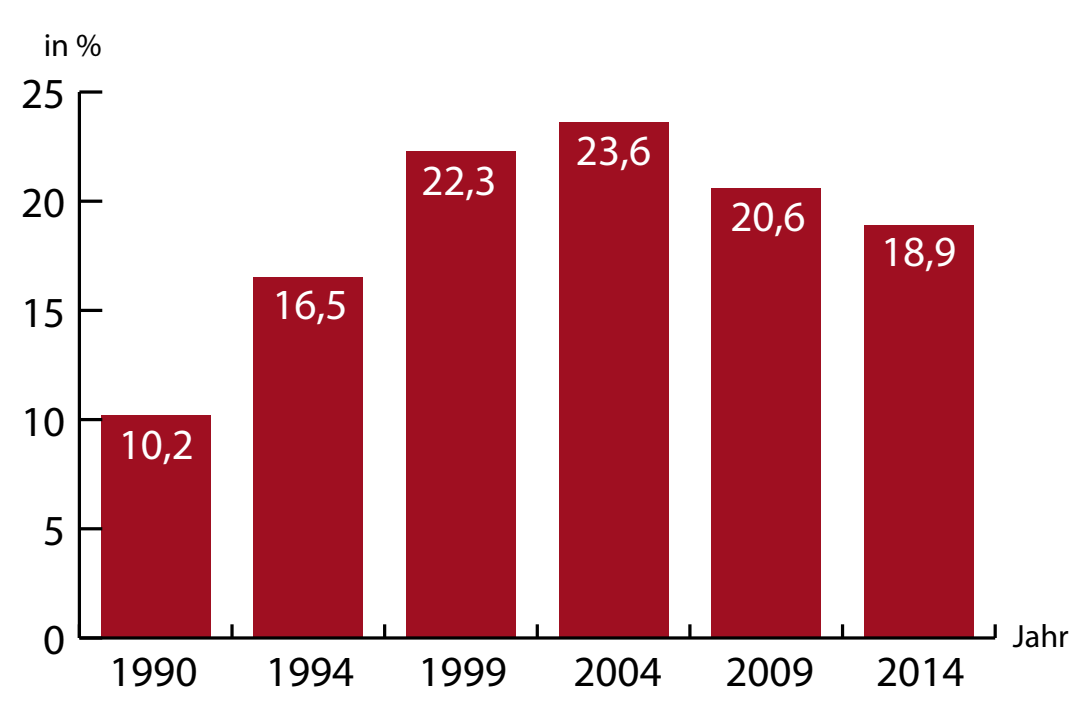

Wahlergebnisse der PDS/ Linkspartei bei den Landtagswahlen 1990 bis 2014

Wahlergebnisse der SPD bei den Landtagswahlen 1990 bis 2014

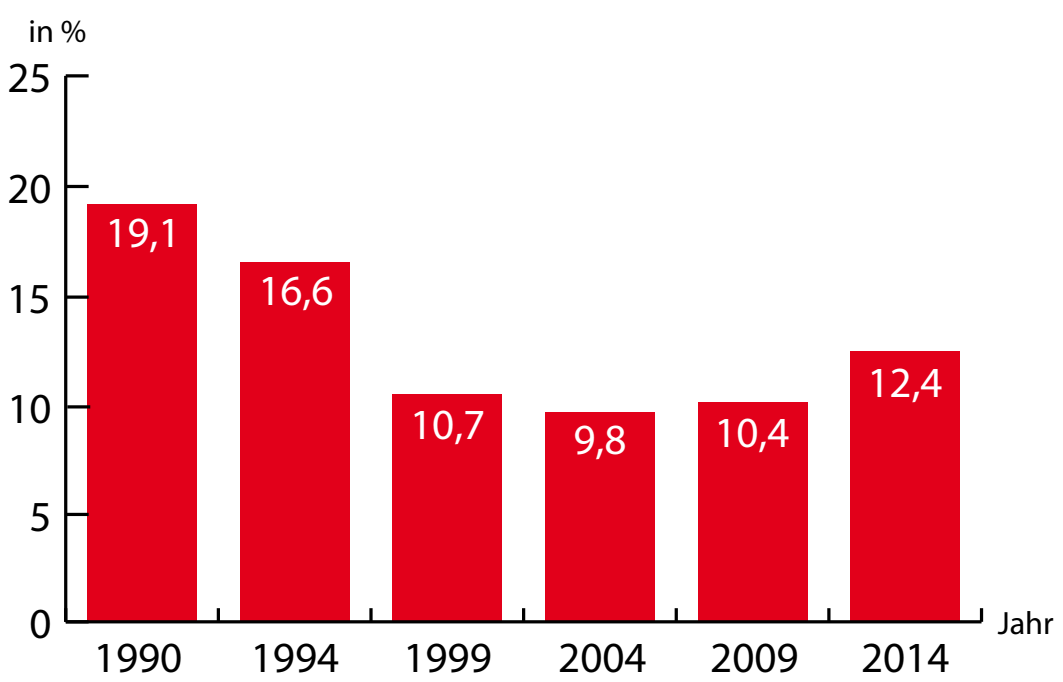

Doch aus der SED stammend, gehörten diese PDS-Exponenten mehr und mehr zu den Älteren und Alten der Partei und machten, gerade auch im Sächsischen Landtag, den Jüngeren Platz. Diese aber wurden weniger von jener lang getragenen Regierungsverantwortung geprägt, die in der Haltung vieler aus der SED stammender PDS-Politiker weiterwirkte. Wichtiger war ihnen die Freude daran, links zu sein und somit voller Selbstgewissheit für das Wünschenswerte, ja alternativlos Gute eintreten zu können. Erfahrungen mit eigenen Fehlern, typisch für viele ehemalige SED-Politiker, fehlten ihnen. Deshalb wurden sie viel ideologischer und weniger pragmatisch als ihre Vorgänger. Obendrein waren sie nun in der - auf Parteitagen inzwischen majorisierenden - Gesellschaft westdeutscher Linker. Die aber haben kaum einmal schon Regierungsverantwortung getragen und pflegen eine gesinnungsethische Ausrichtung an stark ideologisch gefärbten Positionen.

Dies alles - der Generationenwechsel, das Aufgehen in einer wenig pragmatischen Bundespartei sowie eine deutlich polemische Akzentzuspitzung - wirken nun im sächsischen Landesverband der LINKEN zusammen. Eben das erschwert es ihm, in überzeugender Weise auf ein Bündnis mit SPD und GRÜNEN als den anderen beiden Parteien zwischen Mitte und linkem Bereich einzugehen. Umso fataler wirkt sich das für reale oppositionelle Machtperspektiven in Sachsen aus, als dort die PDS bzw. LINKE seit 1999 viel stärker ist als die SPD. 1990 nur 10,2 Prozent der Stimmen erzielend, steigerte sie nach einem Fast-Gleichstand mit der SPD bei 16,5 Prozent im Jahr 1994 - bis 2004 ihren Stimmenanteil auf 23,6 Prozent, um erst zehn Jahre später wieder bei 18,9 Prozent - immer noch klar vor der sächsischen SPD - zu landen. Solange das so bleibt, fiele der LINKEN mit Recht in einem Regierungsbündnis das Amt des Ministerpräsidenten sowie die führende Rolle zu. Eben das lässt die SPD vor einem solchen Zusammengehen zurückweichen, zumal es vermutlich die mehrheitlichen inhaltlichen Wünsche der Gesamtwählerschaft verfehlen würde. Hinzu kommen bei der SPD mancherlei aus jenen Zeiten nachwirkende Aversionen, als der Vorgängerpartei der LINKEN jede Art von „Sozialdemokratismus" als eine schändliche politische Haltung galt.

Tatsächlich ist die SPD unter allen sächsischen Parteien in der schwierigsten Lage. Von 1990 rund 4.400 Mitgliedern ist sie bis heute auf etwa 4.300 sogar ein wenig abgesunken und hat auch ihren Stimmenanteil von 19,1 Prozent bei der ersten Landtagswahl nie wieder erreicht. Bis 2004 auf ganze 9,8 Prozent absinkend, erholte sie sich 
2014 auf gerade einmal 12,4 Prozent. Im Grunde befindet sich Sachsens SPD zwischen der CDU als Amboss und der LINKEN als Hammer: Jegliche linke Position kann die Linkspartei klarer, visionärer, ja für viele Wähler auch attraktiver formulieren als die SPD; und jede „Position der Mitte“ lässt sich auch von der CDU vertreten, zumal nach deren „Sozialdemokratisierung“. Das zwingt die SPD entweder in die Position als - im Vergleich zur LINKEN - „kleinerer Oppositionspartei“ oder als Juniorpartner an die Seite der CDU. Aus beiden Rollen konnte sie bislang allerdings nicht viel politisches Kapital schlagen. Erst eine CDU, die sich wieder klar um den rechten Rand bemühte, und eine Linkspartei, der die „Reinheit der Lehre" über realistische Positionen ginge, öffnete der SPD merklichen politischen Entfaltungsraum, in dem sie versuchen könnte, an ihre glanzvolle Rolle vor der Nazizeit anzuschließen.

Für die sächsische Demokratie ist das unschön, ja ungut. Es steht nämlich keine wirklich attraktive Alternative zur Herrschaft der CDU in Aussicht. Das aber setzt die CDU nicht unter wirklich großen Leistungsdruck und leistet deren Erschlaffen Vorschub. Deshalb wird die CDU wohl noch längere Zeit mit jeweils wechselnden Koalitionspartnern den Freistaat Sachsen regieren.

Nach der zweimal mitregierenden SPD und der einmal zum Zug gekommenen FDP könnten dabei die GRÜNEN für neue Akzente sorgen. 1990 mit 5,6 Prozent der Stimmen in den Landtag gelangt und bis 2004 dann an der Sperrklausel gescheitert, erlangten sie - nach damals 5,1 Prozent - im Jahre 2009 zwar 6,4 Prozent, fünf Jahre später aber wieder nur 5,7 Prozent. Auch haben sie - über die Jahre ziemlich stagnierend - in Sachsen nicht mehr als rund 1.300 Mitglieder und wirken wie in einer Sackgasse ihrer Entwicklung. Vor der Landtagswahl von 2014 war zwar ein aus ihr ausbrechendes Bündnis mit der CDU im Gespräch, ja galt in den Reihen der Sachsenunion nicht einmal als unattraktiv. Bei den GRÜNEN wirkte die damalige Fraktionsvorsitzende und Spitzenkandidatin, Antje Hermenau, sogar höchst aktiv auf ein solches Bündnis hin und setzte dafür ihre politische Laufbahn aufs Spiel. Doch es zeigte sich, dass die meisten - oft auch überdurchschnittlich jungen - Mitglieder der GRÜNEN sich klar als links und somit der SPD sowie der LINKEN viel näher empfinden als der CDU. Diese Partei erscheint ohnehin vielen GRÜNEN wie der Inbegriff all dessen, was sie emotional ablehnen. Der Schnittmengen gäbe es zwar etliche, weil das Nachhaltigkeitsprinzip nun einmal vom Umgang mit der Natur über den mit der Energie bis hin zur finanziellen Nachhaltigkeit ein konservatives Prinzip ist. Also findet es

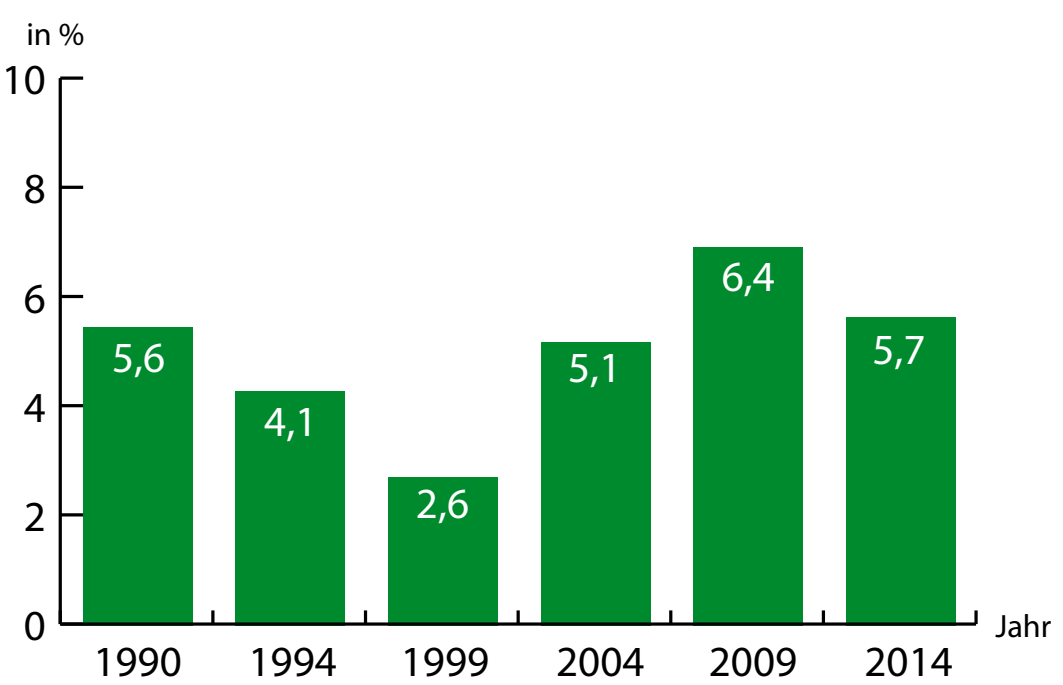

auch in der CDU weitgehende Unterstützung. Doch im Grunde waren die GRÜNEN zufrieden damit, dass ihnen mangels eines ernsthaften Koalitionsangebots der CDU jene Zerreißprobe erspart blieb, die ihnen ein solches Bündnis beschert hätte. Aus ihm entstehende innerparteiliche Streitigkeiten hätten fünf Jahre später vielleicht auch den Wiedereinzug in den Landtag gefährden können - gerade so, wie es der FDP nach fünfjähriger Koalition mit der CDU widerfahren war.

Ohnehin war die FDP schon zwischen 1994 und 2004 nicht mehr im Landtag gewesen. 1990 mit 5,3 Prozent gestartet, sank sie 1994 auf 1,7 Prozent, fünf Jahre später gar nur 1,1 Prozent ab, um dann 2004 mit 5,9 Prozent wieder in den Landtag zu gelangen und 2009 mit 9,95 Prozent ihr bisheriges Spitzenergebnis zu erzielen. 2014 aber misslang ihr mit 3,8 Prozent der Wiedereinzug ins Parlament. Mit einem Abstieg von rund 25.000 Mitgliedern im Jahr 1990 auf heute etwa 2.300, agiert sie obendrein vor dem Hintergrund einer wirklichen Misserfolgsgeschichte. Zwar kann

Wahlergebnisse der FDP bei den Landtagswahlen 1990 bis 2014

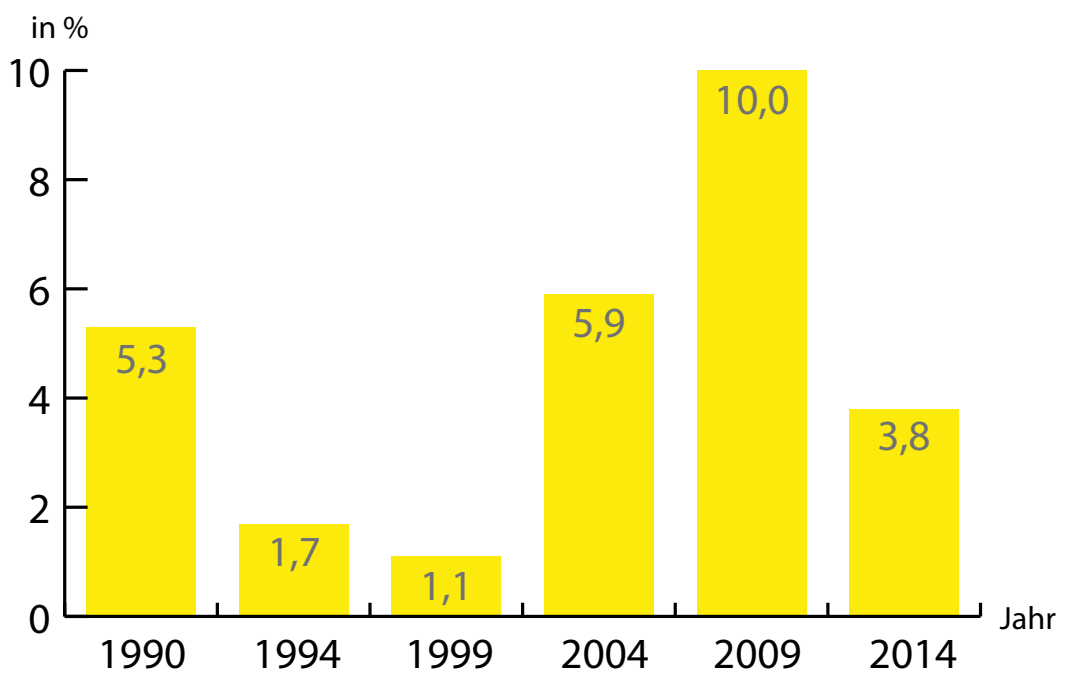


sich die FDP in Sachsen weiterhin auf eine zwar abnehmende, doch immer noch nennenswerte Anzahl von Bürgermeistern und kommunalen Mandaten stützen. Allerdings ist das ein Erbe der LDPD, die zur Zeit der Wiedervereinigung sogar größer war als die sich mit ihr verbindende westdeutsche FDP. Doch alle ostdeutschen Landesverbände der FDP erodierten anschließend, so dass die Entwicklung der sächsischen FDP keine Ausnahme darstellt.

$\mathrm{Zu}$ den Ursachen dieser Entwicklung gehört, dass liberales Denken zu DDR-Zeiten weitgehend ausgetrocknet war, nach der Wiedervereinigung gerne - und durchaus diffamierend - mit dem „Neoliberalismus" zusammengebracht wurde und außerdem seine soziale Trägerschicht verloren hatte. Selbständige Gewerbe- und Handelstreibende gab es in der späten DDR nämlich fast gar nicht mehr; die wirtschaftlichen und gesellschaftlichen Turbulenzen nach der Wiedervereinigung erschütterten erst recht die Stabilität potentiell gewerbebürgerlicher Schichten; und wer anschließend wirtschaftlich erfolgreich war, stand in Sachsen alsbald der CDU näher als der FDP. Bildungsbürgerliche und akademische Schichten wiederum, bis weit hinein ins Dresdner Kulturbürgertum, orientierten sich auf die GRÜNEN hin. Das alles war einer Stabilisierung der sächsischen FDP sehr abträglich. Weil aber rundum liberales politisches Denken, von der Ordnungspolitik in der Wirtschaft bis zur Befürwortung von Eigenverantwortung im persönlichen Leben, deshalb keinen klaren, nicht von anderen politischen Strömungen überlagerten politischen Ausdruck mehr findet, nimmt Sachsens Demokratie durchaus Schaden. Repräsentative Demokratie samt Marktwirtschaft ist ohne wirkungsmächtigen Liberalismus nämlich nicht auf Dauer zu haben.

\section{Sachsens Parteien und ihre Leistungen für die Demokratie}

Woran aber lässt sich im Einzelnen ablesen, was Sachsens Parteien zu Sachsens Demokratie beigetragen haben? Am besten ist es, zunächst auf die Rolle der Parteien im politischen Entscheidungssystem Sachsens zu blicken, also auf die Erfüllung der Aufgaben der Landtagsfraktionen beim Zusammenwirken mit der Staatsregierung. Anschließend ist zu beurteilen, wie gut ihnen die Repräsentation des Volks gelungen ist. Gerade sich demokratisch zur Wahl stellende Parteien verbinden nämlich das auf vordemokratische Zeiten zurückgehende Repräsentationsprinzip mit dem Demokratieprinzip.

\section{Regierungsbildung}

Was ist die zentrale Aufgabe, die in Deutschland ein Parlament, und somit die Gruppe der dort versammelten regionalen und überregionalen Parteiführer, zu erfüllen hat? Es gilt, eine Regierung ins Amt zu bringen und sie - möglichst bis zur ordnungsgemäßen Neubildung einer Regierung nach der nächsten Wahl - nicht nur im Amt zu halten, sondern auch mit verlässlicher Handlungsfähigkeit auszustatten. Dann nämlich kann ziemlich krisenfrei regiert werden, während die Regierung von der sie tragenden Mehrheit insofern kontrolliert wird, als sie gehalten ist, innerhalb der eigenen Reihen nicht mehrheitsfähige Politik zu unterlassen.

Dass die Erfüllung dieser Aufgabe gerade keine Selbstverständlichkeit ist, zeigt der Blick auf andere ehedem realsozialistische Staaten. In der - neuerdings wieder mit schlimmen Zuständen geschlagenen - Ukraine, zuvor auch in Polen, gab es lange Zeit vor allem Reibungsverluste im Zusammenwirken zwischen Parlament und Regierung. Länder wie Tschechien oder gar Rumänien hatten obendrein wiederkehrende Schwierigkeiten mit der Stabilität und Berechenbarkeit ihrer Regierungen. Und Länder wie Weißrussland und Russland lösten derlei Probleme schlicht durch die Errichtung von Machtvertikalen, das heißt durch die Wiedereinführung autoritärer Regierungsweisen. Vor diesem Hintergrund, und im Vergleich gerade mit Sachsen-Anhalt, erkennt man hier eine lobenswerte Leistung der sächsischen Parteien zumindest jener drei, welche bislang die Chance hatten bzw. nutzten, die Staatsregierung zu stellen. Zur Zeit des Ministerpräsidenten Kurt Biedenkopf, und selbst noch bei der krisenhaften Regelung seiner Nachfolge, war Regierungsstabilität ohnehin kein Thema. Doch auch nach dem Verlust der - bis dahin die Regierungsbildung sehr erleichternden - absoluten CDU-Mehrheit fanden sich CDU und SPD trotz großer Gegnerschaft 2004 schnell zusammen und regierten stabil. Allerdings scheiterte die Neuwahl des Ministerpräsidenten Milbradt nach der Bildung dieser Koalition im ersten Wahlgang, vermutlich aufgrund „offener Rechnungen“ in den eigenen Reihen. Recht einfach war dann 2009 die Einrichtung der CDU/FDP-Koalition, die bis 2014 bestand, als die FDP den Wiedereinzug in den Landtag verfehlte. Und selbst die Bildung der CDU/SPDRegierung im Jahr 2014, die besonders intensive Verhandlungen brauchte, war zu keinem Zeitpunkt gefährdet - weder als Ziel der Verhandlungsteams noch beim folgenden Parteireferendum in der SPD oder gar in den Reihen der CDU. Nie also verweigerten sich bislang alle denkbaren Koalitionspartner der CDU. Und aufgrund sehr klarer Wahlergebnisse war nie umstritten, von welcher Partei die Initiative zur Regierungsbildung auszugehen hatte.

Kleinere Krisen löste allein die CDU aus. Das 
geschah zwar selten, doch immer dann, wenn sich in ihr die Führungsfrage neu stellte. Zum ersten Mal war dies, als Kurt Biedenkopf nach einem triumphalen Wahlsieg leichtfertig von seiner „letzten Amtszeit" sprach, ohne dann auch erkennbar die Weichen hin auf die Nachfolge zu stellen. Zum zweiten Mal kam es so, als Georg Milbradt in der Krise um die Sächsische Landesbank erleben musste, dass sogar frühere Unterstützer aufgrund seiner - so empfundenen - Erfolglosigkeit im Wahlkampf sowie wegen seines innerparteilichen Führungsstils von ihm abgerückt waren.

Doch abgesehen von diesen zwei kurzen Störungen haben Sachsens Parteien es nie unterlassen, eine wirklich handlungsfähige Regierung zu bilden. Obendrein haben sie es bei den Wahlen stets geschafft, die Stimmen in solcher Verteilung auf sich zu ziehen, dass Experimente in der Art Sachsen-Anhalts mit seiner tolerierten Minderheitsregierung nie erwogen werden mussten. Mit Ausnahme der Regierungsbildung von 2014 war jeweils auch schon im Wahlkampf klar, mit wem die CDU - falls nötig - eine Koalition eingehen wollte. Doch sogar damals galt es vielen als unwahrscheinlich, dass der Flirt zwischen Antje Hermenau und der CDU in eine Koalition münden würde. Deshalb wussten die Wähler stets, was sie mit ihren Stimmen bewirken und höchstwahrscheinlich nach der Wahl erhalten würden. Besser aber lässt sich Repräsentation und ein parlamentarisches Regierungssystem nicht mit Demokratie verbinden - was ohne zusammenhaltende und stark geführte Parteien nicht hätte gelingen können.

\section{Regierungskontrolle}

Haben Parteien - durch geheime Ministerpräsidentenwahl im Landtag und, gegebenenfalls, durch dem vorangehende Mitgliederentscheide und Sonderparteitage - erst einmal für die Installierung einer Regierung gesorgt, so muss diese auch kontrolliert werden. Ziel der Regierungskontrolle ist es, kontinuierlich solchen Druck auf die Regierung auszuüben, der sie zu einer für das Land - und dann auch für den eigenen Einfluss vorteilhaften Politik anhält. Natürlich nimmt die Regierungskontrolle unterschiedliche Formen je nach dem an, ob sie von einer Oppositionspartei oder einer regierenden Partei ausgeübt wird. Kontrolldruck seitens der Opposition wird nämlich vor allem über Medien und Öffentlichkeit ausgeübt, trifft aber auf mannschaftliches Abwehrverhalten seitens der Regierung und der sie tragenden Parlamentsmehrheit. Oppositionelle Regierungskontrolle ist deshalb zwar öffentlich gut sichtbar, bleibt kurzfristig - nämlich bis zum nächsten Wahlkampf - aber meist ohne ebenso gut sichtbare Folgen. Regierungskontrolle seitens der regierungstragenden Funktionen hingegen wird meist unterhalb der Schwelle öffentlicher Wahrnehmbarkeit durchgeführt, um nämlich der Opposition nicht leichtfertig Angriffsflächen zu bieten. Sie ist aber umso wirkungsvoller, je plausibler sie sich auf wirkliche Politikfehler oder reales Fehlverhalten von Regierungsmitgliedern bezieht. Allerdings wird in der Regel versucht, die aufgrund solcher Kontrolle gezogenen Konsequenzen ebenfalls unterhalb öffentlicher Wahrnehmungsschwellen zu halten. Derlei Regierungskontrolle ist somit effektiv, doch für nicht-professionelle Politikbeobachter viel schwerer zu erkennen.

PDS und SPD, neben der CDU als einzige Parteien seit 25 Jahren durchgängig im Landtag, haben ihre Kontrollaufgaben wahlweise polemisch oder konstruktiv, lautstark oder zurückhaltend, poin-

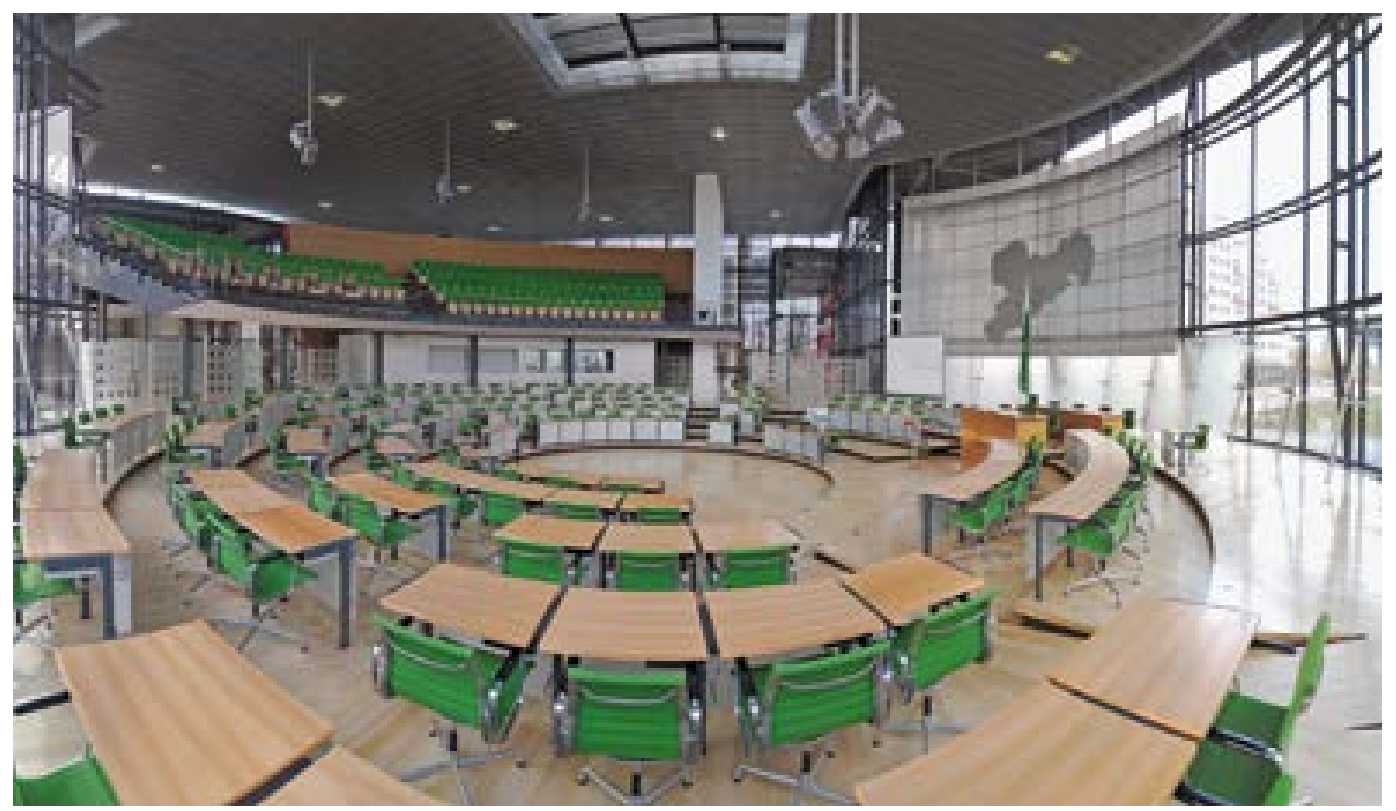

Sächsischer Landtag in Dresden, Plenarsaal Foto: Ralf Roletschek/ fahrradmonteur.de 
tensüchtig oder - wie der PDS-Finanzexperte Ronald Weckesser bei seinem bundesweit aufsehenerregenden alternativen Haushaltsentwurf mit beeindruckender Sachkompetenz versehen. Dass diese Leistung den Oppositionsparteien an den Wahltagen vergleichsweise wenig nutzten, hat ganz wesentlich damit zu tun, dass die CDU sich lange Zeit recht wenige Blößen gab. In Gestalt von Kurt Biedenkopf stellte sie sogar lange Zeit einen wie es vielen schien - im Grunde „überparteilichen Ministerpräsidenten“, den heftig anzugreifen in Sachsens „monarchischer Republik“ wenig nutzte. Zur Zeit der Ministerpräsidenten Georg Milbradt und Stanislaw Tillich stellte sich dann wieder republikanische Normalität ein. Ein Übriges tat der Generationenwechsel bei der LINKEN, dem Pragmatiker wie Weckesser nicht nur vom Stil, sondern auch vom Politikansatz her zum Opfer fielen. Auch die GRÜNEN betrieben ein klar konfrontatives Oppositionsverhalten. Gleiches unternahm die NPD, wobei deren Opposition sich nicht selten durch Rüpelhaftigkeit und Verzicht auf parlamentarisch angemessene Umgangsformen kennzeichnete. Ganz anders nahm hingegen die 2014 neu in den Landtag gelangte AfD ihre Oppositionsrolle war: als konstruktive Opposition, und vor allem darauf bedacht, lieber als ,bessere CDU“ denn als Nachfolgerin der NPD aufzutreten.

Hingegen hat die CDU gerade zur Zeit des Ministerpräsidenten Biedenkopf ihre Kontrollfunktion nicht für sonderlich vordringlich gehalten. Die meisten teilten nämlich den Eindruck, „König Kurt" mache die Sache schon richtig. Deshalb verstand sich die CDU-Landtagsfraktion damals eher als Unterstützungstruppe denn als kritischer Partner der Staatsregierung. Unzufrieden mit diesem Stil und mit so manchen Entscheidungen der lange Jahre allein regierenden Partei, griff dann die Wählerschaft kontrollierend-korrigierend ein: 2004 brachte sie die CDU um die absolute Mehrheit und legte ihr einen sehr weitgehenden personellen Umbruch nahe. Hinzu kam vielerlei inner- fraktioneller Groll gegenüber dem Ministerpräsidenten Milbradt als Sieger im Machtkampf mit seinem Amtsvorgänger. Ergebnis war, dass Milbradt des Wohlwollens der CDU-Fraktion nie in gleicher Weise sicher sein konnte wie Biedenkopf. Er reagierte darauf mit intensiven Kontrollund Abschirmungsversuchen, was seine Lage nicht wirklich verbesserte. In der kritischen Situation um die Krise der Sächsischen Landesbank herum brachte ihn dann zum Amtsverzicht, dass ihn die eigene Fraktion nicht mehr ausreichend vor dem Kontrolldruck der Opposition abschirmte. Sein Nachfolger Tillich lernte aus alledem, zeigte wenige Kanten und bot kaum mehr Angriffsflächen, achtete sorgfältig auf innerfraktionelle Absicherung und konnte deshalb solange recht reibungsarm regieren, bis die gesamtdeutsche Einwanderungskrise auch Sachsen erreichte und auch den Regierungschef nicht mehr bella figura machen ließ.

In das CDU-typische Muster seiner sehr hinnahmebereiten Regierungskontrolle durch regierungstragende Parteien fügten sich zu ihren jeweiligen Regierungszeiten auch die FDP und die SPD. Bei der SPD führt allerdings Unmut über eine „zu willfährige" Haltung ihrer Minister während der ersten CDU/SPD-Koalition zu besonders detailreichen Koalitionsverhandlungen vor dem Eingehen der jetzt regierenden Koalition. Hingegen war die FDP so zufrieden mit ihrem Aufstieg zur Regierungspartei gleich nach ihrem großen Wahlerfolg im Jahr 2009, dass sie ihre Kontrollfunktion ziemlich vernachlässigte.

Unterm Strich ist der Freistaat Sachsen nicht schlecht regiert worden. Dazu wird neben vernünftigen Grundsätzen der Regierungsarbeit und guten Vorarbeiten der Ministerialbeamten gewiss auch die parlamentarische Regierungskontrolle beigetragen haben. Das wichtigste Zurückbleiben hinter dem Wünschenswerten an Kontrolldruck gab es seitens der für die Regierungskontrolle zuständigen Landtagsfraktionen wohl bei der

\footnotetext{
Sächsische Staatskanzlei in Dresden, Sitz des

Ministerpräsidenten Foto: wikimedia, Norbert Kaiser
}

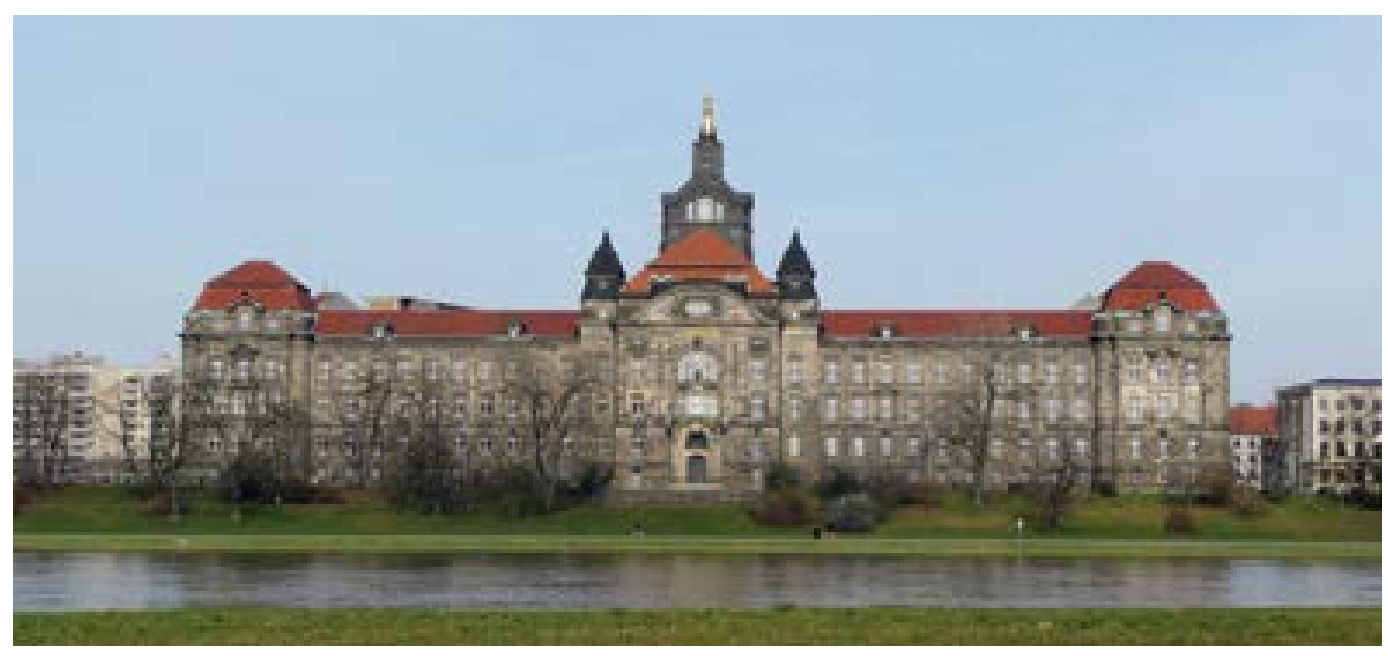


Schulpolitik. Dort tat sich nämlich ein im Grunde lange schon absehbarer Lehrermangel für die nächsten Jahre auf, vor dem zu warnen und den abzuwenden gerade die jeweils regierungstragenden Fraktionen zu wenig Ehrgeiz und politische Kraft entwickelten. Neuerdings kam mancherlei gouvernementales Versagen bei der Bewältigung der Einwanderungs- und Integrationskrise hinzu, wobei das unterschiedliche Kontrollverhalten von Sachsens Parteien sich, bemessen am bislang Üblichen, untypisch stark an ideologischen Grundüberzeugungen orientiert. Insgesamt zeigt sich, dass selbst eine mit inzwischen auch strukturell verfestigter Macht ausgestattete CDU politisch nicht machen kann, was sie will - und das ist auch gut so für Sachsens Demokratie.

\section{Gesetzgebung}

Nicht schlecht sind auch die Leistungen von Sachsens Parteien bei der Gesetzgebung des Freistaates. Da eine detaillierte Würdigung notwendigerweise auf einzelne Gesetzesprojekte eingehen müsste, etwa auf das Kulturraumgesetz oder zuvor auf den Prozess der Verfassungsgebung, lassen sich hier keine Einzelheiten bilanzieren. Doch auf die wichtigste Errungenschaft muss hingewiesen werden, nämlich auf die - 2013 erfolgte - verfassungsmäßige Verankerung der Pflicht, einen ausgeglichenen Staatshaushalt vorzulegen. Damit wird auf Dauer gestellt, was schon seit 2006 Staatspraxis sowie bereits zu Zeiten der für den Wiederaufbau nötigen Schuldenaufnahme ein weithin plausibles Zukunftsanliegen war: eine solide, nachhaltige Finanzpolitik. Gelingt es, sie auch weiterhin durchzuhalten und keine Ausnahmen von der verfassungsrechtlichen Hauptregel zuzulassen, so erhält sich der Freistaat auf Dauer seine Gestaltungsmöglichkeiten und erlaubt künftigen Generationen mehr, als nur auf den von den Vorgängern gelegten Gleisen weiterzufahren. Gerade das aber ist im Sinn der Demokratie. Sie läuft nämlich leer, wenn Zustände nur noch zu akzeptieren, doch nicht mehr zu verändern sind.

Weniger im Sinn der Demokratie ist es, dass von Sachsens Parteien solche Gesetzesinitiativen umsichtig genug vorbereitet und auch nicht ernsthaft genug im Landtag erörtert wurden, die einen sinnvollen Ausbau der jetzt schon verfassungsmäßig vorgesehenen Möglichkeiten der Volksgesetzgebung zum Ziel haben. Insbesondere fehlt weiterhin die Möglichkeit gesetzesaufhebender Volksabstimmungen. Deshalb landet der Streit um parlamentarisch beschlossene Gesetze auch dann beim Verfassungsgerichtshof, wenn die Kernfrage gar keine verfassungsrechtliche, sondern eine politische ist. Die aber wäre besser vom Volk als von Richtern zu beantworten. Hier haben Sachsens Parteien noch nicht den dafür nötigen Mut aufge- bracht, im Bereich der Gesetzgebung die sächsische Demokratie auch mit direkt wirkenden Mechanismen auszustatten. Und wann immer sie ins Feld führen, plebiszitäre Instrumente öffneten solchen Demagogen die Bahn, denen die sächsische Bevölkerung auf den Leim gehen werde, geben sie stillschweigend $\mathrm{zu}$, allzu wenig in die Rahmenbedingungen einer für die Herausforderungen pluralistischer Demokratie fit machenden politischen Bildung investiert zu haben. Gerade in der jetzigen Polarisierung um die Einwanderungspolitik herum kann man sich schwerlich noch länger Illusionen darüber hingeben, wie viel da misslungen ist. Demokratie braucht nun einmal mehr bürgerliche Kompetenzen, als sie die MINTFächer - also Mathematik, Informatik, Naturwissenschaften und Technik - vermitteln.

Freilich ist auch unter den jetzigen Umständen, alles in allem, die sächsische Bevölkerung nicht wirklich unzufrieden mit jener Politik, die während der letzten 25 Jahre in Gesetzesform gegossen wurde. Allerdings zeichnet sich derzeit wachsender Widerstand gegen eine Politik ab, die freilich der Bund zu verantworten, der Freistaat Sachsen - auf der Grundlage eigener Gesetzeslagen - aber gleichsam auszubaden hat: unsere recht unzulängliche Einwanderungs- und Integrationspolitik. Sie dürfte deshalb in den kommenden Jahren zu einem großen Thema gesetzgeberischer Auseinandersetzungen werden. Und je nachdem, welche Parteien dabei für oder gegen solche Forderungen eintreten, die der Bevölkerung als fair bzw. plausibel gelten, wird es bei der nächsten Landtagswahl dann zu einer Umschichtung der Machtverhältnisse kommen. Sollten dann die etablierten politischen Partien geschwächt werden, so wäre das die Folge einer Politik, die aufgerissene Repräsentationslücken nicht durch - auch gesetzgeberisch untersetzte Politik schließen kann oder schließen will.

\section{Repräsentation}

Am schlechtesten von allen Parlamentsaufgaben wurde - nicht nur, aber auch - in Sachsen die Bindegliedfunktion von Abgeordneten und Parteien erfüllt, also die Vernetzung des politischen Entscheidungssystems hinein in die Gesellschaft. Das ist umso fataler, als gerade hier die Leistungsmöglichkeiten und Leistungsnotwendigkeiten von Parteien so gut wie gar nicht durch andere gesellschaftliche oder politische Institutionen ersetzbar sind. Eben hier findet sich denn auch die Achillesferse der sächsischen Demokratie. Allgemeine Politiker- und Systemverachtung, wie sie bei den - und im Anschluss an die - PEGIDA-Demonstrationen immer lauter und unverfrorener geäußert wurde, zeigte das unübersehbar an. Stutzig machte schon in den frühen 1990er Jahren bei empirischen Abgeordnetenstudien das Be- 
fundprofil zur ersten Generation ostdeutscher Landesparlamentarier. Im Vergleich mit ihren westdeutschen Kollegen sahen sie es nämlich als klar weniger wichtig an, auch als regionale Parteiführer zu wirken sowie durch eigene Wahlkreisaktivitäten gerade den von starken Parteien getragenen demokratischen Staat in der - ebenfalls noch im Neuwerden begriffenen - ostdeutschen Zivilgesellschaft $\mathrm{zu}$ verankern. Gewiss war die Zurückhaltung bei der Wahlkreisarbeit damals auch auf die weit überdurchschnittliche, ganz vordringliche parlamentarische Gesetzgebungsarbeit der Parlamentarier zurückzuführen. Doch es waren ein Großteil der Abgeordneten - zumal außerhalb der PDS - vom Karrieretyp und der Persönlichkeitsprägung her einfach keine „Parteileute“, selbst wenn gar nicht wenige zuvor schon in Massenorganisationen und Blockparteien tätig gewesen waren. In die "große Politik“ aber waren die meisten aufgrund der Sonderbedingungen der Friedlichen Revolution geraten.

Deshalb verhielt man sich - damals, nicht mehr heute! - im Wahlkreis oft recht anders als westdeutsche Abgeordnete, die wissen, dass die Basis ihrer Laufbahn genau in den dortigen Parteiorganisationen liegt. Außerdem teilten in der ersten Wahlperiode nach der Wiedervereinigung die zwar populäre, für eine Demokratie aber falsche Vorstellung, ein Abgeordneter habe am besten möglichst wenig mit einer Partei zu tun. Das aber widerspricht völlig der Rolle, die Parteien sowie Abgeordnete als regionale Parteiführer tatsächlich haben. Kern dieser Rolle ist es, der Bevölkerung ein glaubwürdig personifiziertes, durch ihre Parteien als „eingeführten Markenprodukten“ garantiertes und plural im Wettbewerb stehendes Politikangebot zu machen, es zu bewerben und bei der Bewältigung der Parlamentsaufgaben dann auch glaubwürdig in konkretes Handeln umzusetzen.

Doch nicht nur an der mitunter widerwilligen Übernahme einer profilierten Parteiführungsrolle durch die erste Abgeordnetengeneration lag es, dass in Sachsen - wie in allen neuen Bundesländern - die Parteien sich nicht so recht in die Gesellschaft einwurzelten. Das lag schon auch, wie eingangs umrissen, an der Gesellschaft selbst. Parteien wurzeln nämlich sehr stark in soziomoralischen bzw. soziokulturellen Milieus, von denen aus sie Wähler, Mitglieder und tüchtige Führer gewinnen können. Verändern sich jene Milieus oder jene gesellschaftlichen Spannungslinien, entlang derer sich diese Milieus einst politisierten, so verändern sich auch die Parteien, die beiderseits solcher Spannungslinien einst entstanden sind. Und je mehr sich solche Milieus auflösen, umso mehr verdorren überhaupt den Parteien ihre gesellschaftlichen und kulturellen Wurzeln. Dann aber sind sie auch immer weniger in der Lage, eine lebendige Verbindung zwischen Volk und politischem System herzustellen. Durch nichts anderes aber hält man in einer repräsentativen Demokratie deren demokratische Komponente stark.

In den neuen Bundesländern mussten nun freilich - aufgrund der vielen 1990 anstehenden und höchst wichtigen Wahlen - Parteien gerade dort neu entstehen oder sich neu erfinden, wo die sie auf Dauer tragenden oder nährenden Milieus noch gar nicht bestanden oder, abgesehen vom die SED/PDS umbettenden Milieu, keine sonderliche Ausdehnung hatten. Das gab dem Parteiensystem der DDR von 1990 sowie der frühen neuen Bundesländer einen recht virtuellen, einen ziemlich vorgeblendeten Charakter. Demoskopische Studien zeigten denn auch, dass die ersten ostdeutschen Wahlentscheidungen - mit Ausnahme jener für die SED/PDS - sich gar nicht an den ostdeutschen Parteien, sondern an deren westdeutschen „Mutterfirmen“ orientierten. Also mussten - wieder abgesehen von der SED/PDS die Parteien der neuen Bundesländer wirklich „von oben“, ja nachgerade „vom Westen“ her in die Gesellschaft hineinwachsen. Die aber bot, instabil wie sie damals war, dafür keinen guten Mutterboden. Die Folgen solcher Anfänge sind bis heute zu sehen: Ein noch viel geringerer Prozentsatz der Bürger ist überhaupt Mitglied in Parteien, nämlich nur ein Prozent im Vergleich zu rund zwei Prozent, und Parteipolitik gilt im Osten noch weniger als im Westen.

Im Übrigen haben Sachsens staatstragende Parteien vor allem zum rechten Rand hin zwei wichtige Repräsentationsaufgaben nicht ausreichend erfüllt. Erstens haben sie nicht klar genug thematisiert, was viele Leute bewegt, falls solche Themenbereiche von Verbotsschildern politischer Korrektheit umstanden waren. Und zweitens haben sie $\mathrm{zu}$ wenig kommunikative Führung dahingehend ausgeübt, dass der Bevölkerung erklärt worden wäre, ob und wie weit man sich selbst ohnehin schon - oder wenigstens in absehbarer Zeit - mit zwar politisch inopportunen, doch von einem nennenswerten Teil des Volks als dringlich angesehenen Problemen beschäftige bzw. beschäftigen werde. Gerade bei der Einwanderungs- und Integrationspolitik wird das derzeit sichtbar. In solche kommunikativen Lücken aber dringen erfahrungsgemäß Protestparteien ein; und weil diese Repräsentationslücke in Sachsen nun einmal am rechten Rand besteht, müssen die immer wieder intensiven Aufwallungen des Rechtsradikalismus in Sachsen nicht wundern. Für die Repräsentationsaufgabe der Parteien ist obendrein von Belang, dass - wie oben gezeigt die Zahlen der Parteimitglieder in den letzten 25 
Jahren sehr stark gesunken bzw. kaum gestiegen sind. Im Fall zumal der SPD, doch auch bei Bündnis 90/Grünen und FDP sind die Mitgliederzahlen gar dramatisch gering. Als Folge dessen fällt es den Parteien immer wieder schwer, die in Aussicht stehenden Mandate - zumal jene auf kommunaler Ebene - angemessen zu besetzen. Deshalb fallen sie bei zwei demokratiewichtigen Parteifunktionen besonders weit hinter das Wünschenswerte zurück: bei der Rekrutierung neuer Parteimitglieder - als jener „Personalmarkt“, auf dem faktisch die Staatsämter vergeben werden. Die Folge ist eine unzulängliche Ausschöpfung des in Sachsens Gesellschaft tatsächlich vorhandenen politischen Potentials. Das aber schadet der sächsischen Demokratie durchaus.

\section{Sachsens Parteien im Urteil der Bürger und die Wirklichkeit}

Auch in Sachsen erkennen viele Bürger einfach nicht, ein wie großer Irrtum es ist, zwar Demokratie zu wollen, Parteien aber abzulehnen. Gemeindeutsch ist jenes aus Umfragen sattsam bekannte Muster, dass nämlich unter den politischen Institutionen besonders wenig Vertrauen gerade die Parteien genießen, desgleichen alle Institutionen, die etwas mit Parteien zu tun haben (vor allem Parlament und Regierung), dass hingegen jene anderen Institutionen besonders viel Vertrauen auf sich ziehen, die überparteilich sind wie Gerichte, Verwaltung und Polizei. Letzteres Vertrauen ist zwar an sich schön, zumal nach den Erfahrungen mit einer sozialistischen Diktatur. Es legt aber einen Grunddefekt unserer politischen Kultur offen: Ganz unzulänglich wird jene zentrale Rolle verstanden, die Parteien als Garanten von Pluralität und freiheitsermöglichendem politischen Streit spielen. Gesellen sich diesem Grunddefekt - wie in der Praxis immer wieder - auch noch Unzulänglichkeiten der Parteien bei der Personalrekrutierung, bei ihrem Finanzierungsgebaren sowie bei ihrer politischen Problemlösungsfähigkeit hinzu, dann erscheint jener Grunddefekt wie einer der Parteien selbst - und nicht wie der einer Bürgerschaft, aus der die Parteien doch hervorgehen.

Dass also in Sachsen eine gut funktionierende Demokratie gewachsen ist, desgleichen ein - verglichen mit den Parteiensystemen anderer ehedem realsozialistischer Staaten - wirklich gut funktionierendes Parteiensystem, das hierzulande also eine Erfolgsgeschichte zu verzeichnen ist: das nehmen die Sachsen entweder wie eine Selbstverständlichkeit wahr, für die man niemanden loben muss, oder umgekehrt wie eine Leistung, für die alle möglichen Instanzen und Akteure zu loben wären, doch gewiss nicht die Parteien. Dabei ist recht unumstritten, was alles geworden und gelungen ist: ein Freistaat Sachsen, der sich mag und von seinen Bürgern im Wesentlichen mit Respekt, ja mit Stolz behandelt wird; der an seine große Geschichte in Kunst, Wissenschaft und technischer Findigkeit erfolgreich anzuknüpfen verstand; der finanzielle Spielräume hat wie kein anderes neues Bundesland und mit seiner Haushaltsdisziplin auch manchen alten Bundesländern ein Vorbild ist; dessen Städte und Dörfer wieder sehr schön anzusehen sind. Gewiss hat dieser Freistaat auch Probleme, zumal durch die demographische Entwicklung und deren, zur Zeit sehr stark in Xenophobie mündenden Neben- und Nachwirkungen. Doch wenn man das Sachsen von vor 25 Jahren in den Bezirken Dresden, Leipzig und Karl-Marx-Stadt mit dem von heute vergleicht, so kann man nur bewundern, was da geleistet wurde.

Wer aber hat das ganz konkret geleistet? Die Bevölkerung allein, oder die Wirtschaft allein, und ganz ohne jene sinnvollen rechtlichen Rahmenbedingungen für erfolgreiches wirtschaftliches Handeln und voranbringende gesellschaftliche Aktivitäten, welche die Parteien über den Landtag setzten? Etwa die Staatsverwaltung allein - ganz ohne eine von Parteien getragene Regierung, die ihr zielführende Vorgaben sowie flexibel zu nutzende Spielräume gab und für die benötigten gesetzlichen Regelungen auch parlamentarische Mehrheiten organisierte? Vielleicht die Richterschaft allein, oder die Medien, oder alle jene Elitengruppen aus Kultur und Wissenschaft, die sicher auch Anteil an Sachsens blühenden Landschaften haben? - Aber wohl doch nicht ganz ohne jene sinnvollen bzw. wenigstens hilfreichen politischen Rahmenbedingungen, welche die von den sächsischen Parteien geformte Landespolitik schuf!

Unschwer ist zu erkennen: Diese guten Früchte wurden ganz wesentlich von den Politikern Sachsens ermöglicht - gerade so, wie der Ruin der DDR samt ihrer Wirtschaft eben auch ganz wesentlich von deren Politikern herbeigeführt worden war. Diese sächsischen Politiker, die Mandatsträger von der kommunalen Ebene bis hin zu Sachsens Bundespolitikern, mit Schwerpunkt bei den Landtagsabgeordneten und den jeweiligen Regierungsmitgliedern: sie alle sind aber zum allergrößten Teil nicht nur Parteimitglieder, sondern in der Regel auch höchst einflussreich in ihren Parteien, ja gerade die Führer ihrer Parteien von der Lokalebene bis zur Landesebene. Wer also vom Gelingen des Neuaufbaus und der Demokratie Sachsens spricht, der darf von den Leistungen der sächsischen Parteien nicht schweigen - zumindest dann nicht, wenn er denn fair urteilen will.

\section{Autor}

Prof. Dr. Werner J. Patzelt Gründungsprofessor des Instituts für Politikwissenschaft der TU Dresden TU Dresden Institut für Politikwissenschaft

Lehrstuhl für Politische Systeme und Systemvergleich 01062 Dresden 